\title{
Professional Staffing Practice of Academic Anesthesia Departments in the United States
}

\author{
Steven Ginsberg ${ }^{1}$, Jonathan Kraidin ${ }^{1}$, Christopher Gallagher ${ }^{1}$, Don R. Hoover ${ }^{2}$, Alann Solina ${ }^{1}$ \\ ${ }^{1}$ Robert Wood Johnson University Hospital, New Brunswick, USA; ${ }^{2}$ Rutgers University, New Brunswick, USA. \\ Email: ginz1@optonline.net, hofficer@erols.com,Christopher.Gallagher@stonybrook.edu, alsolina@mac.com, \\ Donhoover@aol.com
}

Received March 19 ${ }^{\text {th }}, 2013$; revised April 25 $5^{\text {th }}, 2012$; accepted May $15^{\text {th }}, 2013$

Copyright (C) 2013 Steven Ginsberg et al. This is an open access article distributed under the Creative Commons Attribution License, which permits unrestricted use, distribution, and reproduction in any medium, provided the original work is properly cited.

\begin{abstract}
Background: Academic anesthesia departments are under increasing financial pressure. Many struggle to integrate the priorities of their academic and clinical missions. Previous studies have documented increasing need for monetary institutional support of academic anesthesia departments. In view of current economic and legislative circumstances, it is arguable that the need for support will grow. This survey demonstrates that staffing issues, which are most likely engendered by financial circumstances, have impacted academic anesthesia departments in the United States to the point of having deleterious effects upon clinical safety and resident education. Methods: After IRB approval, we electronically solicited the anonymous response to a 23 question survey from all 133 chairpersons of academic anesthesia departments in the United States. Results: Sixty-two responded electronically, for an overall response rate of $46.6 \%$. Conclusion: The results of this survey suggest that academic anesthesia departments are being financially stressed to the point that education and patient care are affected.
\end{abstract}

Keywords: Off Site; Case Load; Patient Safety; Inadequate Staffing; Non Clinical Time

\section{Introduction}

Many academic anesthesia departments have experienced increasing financial pressure over the past decade, causing an increased requirement for financial support from their Medical Schools and University Hospitals ${ }^{1}$. The etiology of this financial situation is multifactorial. There is a growing Medicare population that requires surgical procedures [1], for which anesthesia services are discounted relative to all other payers (with the exception of Medicaid, and in some cases self-pay patients). The marked proliferation of in-hospital "Off-Site Anesthesia" locations has, in some cases, presented financial challenges, in that these sites (e.g., cardiac catheterization laboratories, endoscopy suite, radiology departments, etc.) are frequently less efficient logistically. Academic salaries, which have risen in response to supply: demand dynamics, have also imposed a financial burden upon academic anesthesia departments [2].

${ }^{1}$ Seventh and eighth year follow-up on workforce and finances of the United States anesthesiology training programs: 2007 and 2008. Kheterpal S., Tremper K., Shanks A., Morris M. Anesth Analg 2009; 109:897-9.
The future promises increasing financial challenges. The financial impact of a struggling global economy and burgeoning state budget deficits may visit financial hardship upon many academic institutions, especially those that derive funding from state sources. The effect that the Patient Protection and Affordable Care Act has had upon State Budgets remains to be seen [3]. In its present form, the law mandates a progressive decrease in federal subsidy to states for newly covered Medicaid patients from $100 \%$ in 2014 to $90 \%$ in 2020 , and thereafter [4]. Additionally, the Healthcare Reform mandates increased payment for Medicaid services, rendered by physicians to Medicare levels in 2013 and 2014, to be subsidized in whole by the federal government. However, the expiration of this mandate and subsidy in 2015 may impose an issue upon state budgets, in which states would have to own the financial liability of the disparity between what the legislation mandates for physician reimbursement rate and the actual rate that is paid. Many states are also facing the additional problems of a recession-driven decrease in tax revenues and unfunded pension liabilities [5]. Finally, "Pay-For-Performance" incentive initiatives are certain to change into "Penalize- 
For-Lack-Of-Performance" initiatives [6]. Some or perhaps all of these issues will have an effect on federal, state, and hospital budgets, and will undoubtedly have a significant effect on healthcare finances.

Operational management of academic anesthesia departments will require the integration of multiple simultaneous priorities including financial stability, educational and academic pursuits, patient safety, and satisfying the clinical mission of the University Hospital. Academic anesthesia departments will need to optimize operational efficiencies and secure maximum monetary and non-monetary infrastructural support.

Past surveys performed and published by Tremper and colleagues $^{1}$ have delineated financial, manpower, and monetary support trends for Academic Anesthesia departments. The present survey focuses on staffing issues, with particular reference to those that affect patient safety and resident education. In view of the aforementioned financial circumstances, these issues will likely be increasingly important over the next decade, as growing economic pressure permeates its way into our everyday practice of Academic Anesthesia.

We believe that the results of this survey will serve as a reference for institutional comparison and help to establish normative data. This survey may also serve to point out some disturbing practice patterns, which may need to be addressed in the future.

\section{Methods}

After Institutional Review Board approval at Robert Wood Johnson Medical School, an electronic email-mediated request to participate in our survey was sent to all 133 Chairpersons of academic anesthesia departments in the United States. The survey was sent out electronically seven times between June of 2010 and November. The survey and its results were tabulated in an anonymous fashion using the Google ${ }^{\mathrm{TM}}$ survey tool. The authors did not receive any information that could identify the participants. The email invitation provided a link to a survey web page.

The survey consisted of 23 questions (survey questions shown in Appendix), which could be answered electronically for on-line submission. Survey responders were instructed to answer the survey only for their main University Hospital clinical campuses. The data analysis was done using SAS 9.3. The data was skewed, with the mean frequently substantially larger than the great majority of observations for many variables. In particular, ratios with low denominator values can easily skew the data. Therefore, to be consistent, the median, lower $25^{\text {th }}$ quartile, upper $75^{\text {th }}$ quartile and the range were reported for all variables. Using the upper and lower quartiles, one can see the central range of the programs.

\section{Results}

The survey was sent to 133 institutions. Sixty-two institutions replied with completed surveys, yielding an overall response rate of $46.6 \%$. Table 1 summarizes caseload data. The median total number of cases that were performed per academic center was 18,200, with the vast majority of cases being done in the main operating room suite $($ median $=88 \%$ ). The median number of anesthetizing locations in the main operating room was 22 , with a median of 1.83 cases per main OR location performed per day. While offsite locations represented nearly $25 \%$ of anesthetizing locations, they accounted for only 13\% of the total cases done.

Table 2 summarizes faculty staffing data. The median number of faculty full time equivalents (FTE) per total number of anesthetizing locations was 1.0. The median number of clinical faculty FTE per total cases performed on a daily basis was 0.55 . The median percentage of clinical faculty working on a daily basis was $63 \%$. The median percentage of clinical assignments in which a faculty was working alone was 11.25 . The median percentage of total clinical providers that faculty represent was $44 \%$. The median number of cases performed per total clinical provider on a daily basis was 1.12 .

Table 3 provides summary data concerning non-faculty staffing. The median percentage of clinical workers that were residents and CRNAs on a daily basis was $28 \%$ and $27 \%$ respectively. The median number of residents per program was 22.5. The median number of CRNAs working per clinical day was 11.5 . The median number of residents per total clinical site was 0.72 , and the median ratio of residents to faculty was 0.78 . The median number of residents supervised by a faculty member on a daily basis was 2.0 , with 4 programs out of 61 reporting a $3: 1$ coverage ratio. The median number of residents taking in-hospital overnight call was 3.0, while the median number of CRNAs taking in-hospital overnight call was 0.32. Only $22.9 \%$ of programs had CRNAs taking inhospital overnight call.

Table 4 summarizes data relevant to staffing issues. Seventy-four percent of responding institutions indicated that inadequate clinical staffing affected their ability to provide faculty with adequate non-clinical time. Over $48 \%$ of respondents indicated that inadequate staffing affected their ability to maximize resident education. Approximately $30 \%$ of institutions indicated that inadequate staffing engendered patient safety issues due to suboptimal supervision. $7 \%$ of institutions indicated that they occasionally supervise residents $1: 3$. Over $38 \%$ of institutions indicated that inadequate staffing created obstacles for providing vacation time for faculty.

\section{Discussion}

As financial pressure taxes the ability of academic anes- 
Table 1. Anesthesia case volume and location.

\begin{tabular}{|c|c|c|c|c|c|}
\hline Case Load & $\mathrm{N}$ & Median & Lower $25^{\text {th }}$ Quartile & Upper $75^{\text {th }}$ Quartile & Range \\
\hline $\begin{array}{c}\text { Total \# of cases performed } \\
\text { per year }\end{array}$ & 61 & 18,200 & 14,000 & 26,275 & $5150-69,000$ \\
\hline Total cases per day & 61 & 49.83 & 38.33 & 71.94 & $14.1-188.91$ \\
\hline $\begin{array}{l}\text { Total \# of cases performed } \\
\text { in main OR per year }\end{array}$ & 61 & 16,000 & 12,000 & 20,000 & $1200-64,000$ \\
\hline Total \# of main OR cases per day & 61 & 43.81 & 32.85 & 54.76 & $3.29-175.22$ \\
\hline $\begin{array}{l}\text { \# anesthetizing locations } \\
\text { in main OR }\end{array}$ & 62 & 22 & 16.00 & 30.00 & $4-54$ \\
\hline \# cases a day per main OR location & 61 & 1.83 & 1.64 & 2.19 & $0.22-10.01$ \\
\hline $\begin{array}{l}\text { Total \# offsite cases } \\
\text { performed per year }\end{array}$ & 59 & 2100 & 1000 & 5000 & $0-21,000$ \\
\hline $\begin{array}{l}\text { Total offsite cases per day } \\
\text { (1 Hospital had } 0 \text { off site cases) }\end{array}$ & 59 & 5.75 & 2.74 & 13.69 & $0-57.49$ \\
\hline Total \# offsite Locations & 59 & 6.00 & 5.00 & 10.00 & $0-19$ \\
\hline $\begin{array}{l}\% \text { of total cases that off } \\
\text { site represents }\end{array}$ & 58 & 13 & 6 & 24 & $0-86$ \\
\hline$\%$ of total sites that are off site & 59 & 25 & 17 & 32 & $0-50$ \\
\hline
\end{tabular}

Table 2. Institutional faculty staffing.

\begin{tabular}{|c|c|c|c|c|c|c|}
\hline Faculty Staffing & $\mathrm{N}$ & $\%$ & Median & Lower $25^{\text {th }}$ Quartile & Upper $75^{\text {th }}$ Quartile & Range \\
\hline $\begin{array}{c}\text { \# of clinical faculty FTE/\# Total } \\
\text { Anesthesia locations }\end{array}$ & 59 & & 1 & 0.73 & 1.18 & $0.42-3.75$ \\
\hline \# of clinical faculty FTE/total cases & 61 & & 0.55 & 0.44 & 0.7 & $0.21-1.19$ \\
\hline $\begin{array}{l}\% \text { of clinical faculty } \\
\text { working each day }\end{array}$ & 61 & & 63 & 52 & 71 & $31-90$ \\
\hline $\begin{array}{l}\text { \% of clinical assignments are } \\
\text { individually performed by a } \\
\text { faculty member each day }\end{array}$ & 60 & & 11.25 & 3 & 20 & $\begin{array}{l}0-75 \\
11 \text { said } 0 \text { or always } \\
\text { have a helper }\end{array}$ \\
\hline $\begin{array}{l}\text { \% of clinical providers working on } \\
\text { a given day that are Faculty }\end{array}$ & 59 & & 44 & 36 & 47 & $23-57$ \\
\hline \# cases per clinical provider & 58 & & 1.12 & 0.94 & 1.4 & $0.69-2.74$ \\
\hline $\begin{array}{l}\text { How many clinical faculty FTE's } \\
\text { are working on an average day } \\
\text { (Not on vacation or out after call)? }\end{array}$ & 61 & & 17 & 12 & 23 & $4-72$ \\
\hline $\begin{array}{l}\% \text { Institutions giving next day } \\
\text { off to faculty after call }\end{array}$ & 62 & 96.8 & & & & \\
\hline
\end{tabular}

thesia departments to maintain their academic identity while preserving the priority of patient safety, efficient resource utilization, and maximization of institutional support (both monetary and non-monetary) will become critically important. Previous surveys have provided information pertaining to the monetary support of academic anesthesia departments ${ }^{1}$. The present observational survey focused on staffing issues currently faced by academic anesthesia departments and their faculty.
Staffing patterns in academic anesthesia departments are important markers for important financial issues and limitations currently faced by these departments. It is important for operational managers (Chairpersons and Business Managers) to appreciate how their department's practice fits in with the practice of academic anesthesia throughout the country. It is also important to realize that there are certain practices and staffing issues that need further thought and perhaps corrective action. Finally, we 
Table 3. Institutional staffing of residents, fellows and CRNA's.

\begin{tabular}{|c|c|c|c|c|c|c|}
\hline Non-faculty Staffing & $\mathrm{N}$ & $\%$ & Median & Lower $25^{\text {th }}$ Quartile & Upper $75^{\text {th }}$ Quartile & Range \\
\hline $\begin{array}{l}\text { How many residents do you have in your } \\
\text { program that provide clinical services at } \\
\text { the main clinical site? }\end{array}$ & 62 & & 22.5 & 13 & 36 & $2.3-75$ \\
\hline How many fellows do you have? & 62 & & 2 & 0 & 4 & $0-22$ \\
\hline $\begin{array}{l}\text { How many Residents and fellows do } \\
\text { you have on an average day providing } \\
\text { anesthesia care? }\end{array}$ & 60 & & 12 & 8 & 20 & $2-65$ \\
\hline $\begin{array}{l}\% \text { of clinical providers working on a } \\
\text { given day that are fellows/residents }\end{array}$ & 59 & & 28 & 24 & 39 & $6-60$ \\
\hline \# residents/total clinical sites & 59 & & 0.72 & 0.49 & 1.04 & $0.09-4.13$ \\
\hline Total \# residents/total \# faculty & 62 & & 0.78 & 0.54 & 1 & $0.19-2.32$ \\
\hline Faculty to Resident coverage & 61 & & 2 & 2 & 2 & $\begin{array}{c}0-3 \\
1 \text { reported } 0,1 \\
\text { reported } 1,55 \\
\text { reported } 2,4 \\
\text { reported } 3\end{array}$ \\
\hline $\begin{array}{l}\text { How many residents are there on in-house } \\
\text { overnight call during the week? }\end{array}$ & 62 & & 3 & 2 & 4 & $1-26$ \\
\hline $\begin{array}{l}\text { How many CRNA's do you have working } \\
\text { on most days? }\end{array}$ & 62 & & 11.5 & 6 & 20 & $2-28$ \\
\hline $\begin{array}{l}\% \text { of clinical providers working on a } \\
\text { given day that are CRNAs }\end{array}$ & 59 & & 27 & 20 & 36 & $4-71$ \\
\hline $\begin{array}{c}\text { \% of Programs have CRNAs on call } \\
\text { overnight? }\end{array}$ & 61 & 22.9 & & & & \\
\hline $\begin{array}{l}\text { How many CRNAs are on in-house } \\
\text { overnight call during the week? }\end{array}$ & 60 & & 0 & 0 & 0 & $0-3$ \\
\hline
\end{tabular}

Table 4. Staffing related problems.

\begin{tabular}{|c|c|c|}
\hline Staffing Issues & $\mathrm{N}$ & $\%$ \\
\hline $\begin{array}{l}\text { The average } \% \text { of clinical assignments that are } \\
\text { performed by a faculty member alone }\end{array}$ & 60 & 11.25 \\
\hline $\begin{array}{l}\% \text { of institutions indicating that inadequate } \\
\text { clinical staffing affects their ability to provide } \\
\text { adequate faculty non-clinical time }\end{array}$ & 62 & 74.2 \\
\hline $\begin{array}{l}\text { \% of institutions indicating that inadequate } \\
\text { clinical staffing affects their ability to provide } \\
\text { maximal resident educational experience }\end{array}$ & 62 & 48.39 \\
\hline $\begin{array}{l}\text { \% of institutions indicating that inadequate } \\
\text { staffing creates situations where patient } \\
\text { safety is compromised secondary to } \\
\text { suboptimal supervisory ratios }\end{array}$ & 62 & 32.26 \\
\hline $\begin{array}{l}\text { \% of institutions indicating that inadequate } \\
\text { staffing creates obstacles to providing } \\
\text { vacation time for faculty }\end{array}$ & 62 & 38.71 \\
\hline $\begin{array}{c}\% \text { of institutions reporting that they occasionally } \\
\text { supervise } 3 \text { simultaneous anesthesia sites }\end{array}$ & 60 & 7 \\
\hline $\begin{array}{l}\text { \% of institutions reporting that they only } \\
\text { supervise one clinical site at a time }\end{array}$ & 60 & 1.7 \\
\hline
\end{tabular}

hope that this survey will serve as a framework for future observational inquiries into the clinical practice issues that face academic anesthesia departments.
It is interesting to note that while off-site locations (e.g. cath lab, MRI, CT scan, Interventional Radiology, etc.) represent $25 \%$ of covered anesthesia locations, they provide only $13 \%$ of the caseload. Although unsubstantiated by literary support, it is commonly felt that off-site locations are frequently less efficient operationally than the main operating room suite. The etiology of this relative inefficiency is probably multi-factorial. It includes a lack of strict adherence to block time and start times; educational and administrative meeting times that may not be synchronized with those of the Anesthesia Service, creating non-clinical down time during usual business hours; hospital patient transport issues which are beyond the direct control of the anesthesiologist; the pressure to cater to the scheduling needs of operators who utilize anesthesia services in these off-site locations; the relative inability to cover off-site locations with 1:2 provider ratio because of geographical concerns; and the interspersion of cases at these locations that don't require anesthesia services. Financial concerns will certainly drive the need to maximize the efficiency of these off-site locations. It is predictable that anesthesia services will need to be provided in a dense vertical array of clinical responsibilities in these off-site locations as financial pressure mounts. Since direct institutional financial subsidy 
of a failing clinical operation may be precluded by Stark Law considerations, some anesthesia departments may consider the feasibility of providing services through a Leased Professional Services Agreement at centers where it is difficult to impose logistical efficiencies that are compatible with the economic constraints presently being placed upon academic anesthesia departments. In this fashion the anesthesia department maintains control of the anesthesia services in their jurisdiction without assuming the financial liability of a logistically inefficient service.

The survey identified a significant issue regarding inadequate clinical faculty staffing. The vast majority of responding institutions indicated that inadequate clinical staffing affected their ability to provide faculty with adequate non-clinical time. Nearly half of respondents indicated that inadequate staffing affected their ability to maximize resident education. Perhaps most concerning is the fact that $30 \%$ of institutions indicated that inadequate staffing engendered patient safety issues due to suboptimal supervision, with $7 \%$ of institutions indicating that they occasionally supervise residents $1: 3$, which is not recommended or supported by the ASA, ACGME, or CMS [7]. The upward trend in faculty compensation, failure of Medicare and Medicaid rates to keep up with inflation [8], and the financial pressure that has been imposed upon academic departments as State, Hospital, and Me- dical School budgets are affected by one of the greatest economic recessions in our nation's history [9-11] and has placed many academic anesthesia departments under incredible financial duress. Many departments have been forced to make do with inadequate clinical staffing. Individualized clinical productivity is being pushed to unacceptable levels in some circumstances, with possible effects on resident education and patient safety.

It is critically important for academic anesthesia departments to maintain a level of clinical staffing that is compatible with their educational, academic, and clinical goals. We cannot allow the loss of academic identity, or the compromise of patient safety. Anesthesia departments must be proactive in the preservation of these goals. We must find ways to maximize our operational efficiency, institutional support, and all elements of our revenue cycle. The imposition of logistical efficiency in all clinical arenas is of paramount importance, perhaps especially in off-site venues. Alternative business models (e.g., Leased Professional Service Agreements) may need to be explored. Managed Care contract negotiation may be enhanced in certain circumstances by virtue of having anesthesia departments negotiate with payers as part of a large faculty practice group. It may be possible to maximize financial yield by exploring the possibility of utilizing private anesthesia-specific revenue cycle managers (i.e., coders, billers, and collectors). The use of electronic reconciliation of clinical encounters with submitted bills may be of further economic utility. Roughly half of sur- vey responders indicated that they utilize anesthesia- specific coders, billers, and collectors to manage their revenue cycle, while only $11 \%$ indicated that they use real-time electronic submission of bills for clinical services.

There is a confluence of economic events and trends that will challenge the ability of academic anesthesia departments to maintain their academic identity and provide superior and safe clinical care for our patients. We hope that this survey will help to identify some of the specific issues that we currently face, and help us to prepare for future challenges.

\section{REFERENCES}

[1] "MGMA Physician Compensation and Production Survey: "2010 Report Based on 2009 Data," 2010. http://www.mgma.com/physcomp

[2] “The Medicare Beneficiary Population," 2009. http://assets.aarp.org/rgcenter/health/fs149_medicare.pdf

[3] "Public Law 111-148," 2010. http://www.gpo.gov/fdsys/pkg/PLAW-111publ148/pdf/P LAW-111publ148.pdf

[4] "Public Law 111-52," 2010. http://www.gpo.gov/fdsys/pkg/PLAW-111publ152/pdf/P LAW-111publ152.pdf

[5] "Sales-Tax Revenue Falls at Fastest Pace in Years," 2009 http://online.wsj.com/article/SB123975399974418909.ht $\mathrm{ml}$

[6] "Medicare Pay for Performance (P4P) Initiatives," 2005. http://connected-health.org/policy/medicare-and-medicaid /external-resources/medicare-pay-for-performance-(p4p)-i nitiatives.aspx

[7] "Accreditation Council for Graduate Medical Education," 2011.

http://www.acgme.org/acWebsite/navPages/nav_040.asp

[8] "Medicare Indexation Falls to Half the Rate of Health Inflation," 2007. http://www.medicalnewstoday.com/articles/87373.php

[9] "Hospitals Continue to Feel Lingering Effects of the Economic Recession," 2011.

http://www.aha.org/aha/press-release/2010/100623-pr-rec essionimpact.html

[10] "The Recession in your State," 2008. http://money.cnn.com/2008/11/18/news/economy/states_r ecession.fortune/index.html

[11] "AAMC Study: Recession Forced US Medical Schools to Take New Tack," 2010.

http://www.aafp.org/online/en/home/publications/news/ne ws-now/resident-student-focus/20100920aamc-medschl-st udy.html 


\section{Appendix}

1) What are the total number of OR cases performed each year at main clinical site?

2) What is the total number of cases performed in the main OR per year?

3) How many anesthetizing locations are there in your main OR's?

4) How many "off-site" cases are performed each year at your main clinical site?

5) What is the total number of "off-site" locations at your main clinical site?

6) What is the percentage of clinical assignments individually performed by a faculty member each day?

7) How many clinical Faculty FTE's do you have?

8) How many clinical faculty FTE's are working on an average day (not on vacation or out after call)?

9) Do faculty that are on call in-house overnight get the next clinical day off?

10) How many residents do you have in your program that provide clinical services at the main clinical site?

11) How many fellows do you have?

12) How many Residents and fellows do you have on an average day providing anesthesia care?

13) What is your faculty to resident coverage on average?

14) How many residents are there on in-house overnight call during the week?

15) How many CRNA's do you have working on most days?

16) How many CRNAs are on in-house overnight call during the week?

17) What $\%$ of clinical assignments are individually performed by Faculty (i.e., with no other care provider) on a daily basis at your main academic site?

18) Does inadequate clinical staffing affect your department's ability to reward adequate non-academic time for faculty?

19) Does inadequate clinical staffing affect your department's ability to provide for maximum resident education?

20) Does inadequate clinical staffing create situations in which you are occasionally unable to maximize patient safety because of suboptimal supervisory ratios?

21) Does inadequate clinical staffing create obstacles for providing vacation time for faculty?

22) Does inadequate clinical staffing create obstacles in providing vacation time for faculty?

23) When supervising residents, what is/are the maximum number of clinical sites that a faculty member will supervise at your main clinical site? 